\title{
Exposure to glyceryl trinitrate during gun powder production: plasma glyceryl trinitrate concentration, elimination kinetics, and discomfort among production workers
}

\author{
K GJESDAL, ${ }^{1}$ S BILLE, ${ }^{3} \mathrm{~J}$ E BREDESEN,${ }^{2}$ E BJØRGE,${ }^{3}$ B HALVORSEN,${ }^{3} \mathrm{~K}$ LANGSETH, ${ }^{2}$ \\ P K M LUNDE, ${ }^{2}$ AND E SIVERTSSEN ${ }^{\prime}$ \\ From the Department of Internal Medicine ${ }^{1}$ and Division of Clinical Pharmacology and Toxicology, ${ }^{2}$ Central \\ Laboratory, Ulleval Hospital and University of Oslo, Oslo, and Gullaug Factories, ${ }^{3}$ Dyno Industries, Lier \\ $N-3400$ Lier, Norway
}

ABSTRACT Plasma glyceryl trinitrate (GTN) concentration was studied in 12 volunteers producing gun powder. Serial blood samples were obtained from the cubital vein before and during work at two sites of production; high concentrations of GTN were detected in the plasma. Control specimens from a femoral vein contained much less GTN, indicating that blood in the cubital vein was enriched by dermally absorbed GTN. In the roll mill area concentrations of GTN in the cubital vein were higher than in the press area, but individual factors were also important since some workers consistently had higher concentration of GTN than others. Differences in absorption were more important than differences in the metabolism of GTN since only a small variation in disappearance rate was found after a sublingual test dose of GTN. Moderate changes in pulse rate and blood pressure were noted during the day. The major discomfort experienced was a headache that increased during working hours, but this was not significantly related to GTN concentrations in the air or in the blood from the cubital vein. The observations imply that major efforts should be made to reduce dermal contact with GTN during production work.

Despite improved production procedures and ventilatory measures, workers in gun powder production are still exposed to vapour and semisolid glyceryl trinitrate (GTN) and experience discomfort such as headache during working hours. Owing to rebound vasoconstriction they may also be at risk from cardiovascular complications, including sudden death during leisure time. ${ }^{1-3}$ The present study was performed to examine the route of GTN absorption, to quantify the exposure by assaying plasma concentrations, and to measure the effects of GTN on pulse rate, blood pressure, and headache during working hours.

\section{Subjects and methods}

DESIGN OF MAIN STUDY

The study was carried out from June to August Received 29 September 1983

Accepted 6 January 1984
1982. Seven men and five women aged $21-50$ (mean 38) volunteered to take part in the study. The staff normally rotates weekly to various sites of production, but the schedule was modified in order to study pairs of volunteers working together on successive days (Monday and Tuesday) at the same site for two weeks. Subsequently they moved together to the next site of study. Two sites of work were selected: the roll mill area where the workers are exposed to high levels of GTN and the press area where exposure was thought to be lower. At the differential roll mill mixture, GTN containing powder and addends are transformed by heat evaporation into a semisolid mass that is compressed by a heated roller to a sheet of GTN that is rolled together and brought to a pressure chamber, the press area. Here the sheets are converted to rods and cut.

On each day of the study, blood was collected before the subjects changed into their working clothes at $6 \mathrm{am}$ and at the production site at $9 \mathrm{am}$ 
and $1 \mathrm{pm}$. The blood pressure was measured while resting in a chair, using the disappearance of the sounds (Korotkoff phase 5) as the diastolic value. The pulse rate was counted for one minute before the blood was collected.

Supplementary study-To study the possible contribution of the dermal uptake of GTN to the concentration of GTN in blood in the cubital vein a control study was performed, analysing the plasma GTN concentrations in specimens collected simultaneously from the cubital and femoral veins in three subjects interrupted at work at $1 \mathrm{pm}$ when exposure was high.

\section{TEST DOSE STUDY}

A test dose of $1 \mathrm{mg}$ GTN (Dumex, Copenhagen, Denmark) was given sublingually to the volunteers one Monday morning after the insertion of a plastic cannula into the cubital vein. Blood dripped into precooled sampling tubes and was further prepared as below. Specimens were collected at two minute intervals from four to 14 minutes after the administration of GTN. The plasma half life was derived from the linear part of the semilogarithmic plot of the disappearance curve.

\section{LABORATORY METHODS}

Blood sampling-The forearm was thoroughly cleansed using three pieces of cotton wool soaked in ethanol. Using moderate stasis, blood from the cubital vein was collected into precooled heparinised vacuum tubes (Venoject, Terumo, Japan) that were immediately placed in iced water. After a cooling period of half an hour, the plasma was separated by centrifugation for 10 minutes at room temperature. Using a glass disposable pipette, the plasma was transferred to another heparinised tube and capped and stored at $-20^{\circ} \mathrm{C}$ until analysis, usually within one week. Control experiments confirmed the stability of GTN under these conditions.

Plasma GTN assay was performed after hexane extraction, using a gas chromatograph equipped with an electron capture detector. ${ }^{4}$ The lower limit of detection was $0.22 \mathrm{nmol} / \mathrm{l}(0.05 \mathrm{ng} / \mathrm{ml})$ and the reproducibility was $2 \cdot 5-5 \%$ throughout the range encountered.

Gaseous GTN assay-Air specimens were collected at face level using evacuated 1 litre glass bulbs with stopcocks. After absorbance into ethanol, the GTN was hydrolysed to nitrite by adding potassium hydroxide and heating to $80^{\circ} \mathrm{C}$. After neutralisation by $\mathrm{HCl}$, sulphanilic acid and n-(l-naphtyl) ethylene-diamine-hydrochloride were added and the absorbance read at $540 \mathrm{~nm}$ in a photometer. ${ }^{5}$ Above a concentration of $0.5 \mathrm{mg} / \mathrm{m}^{3} \mathrm{GTN}$, the reproducibility of the method was $10 \%$.

\section{HEADACHE}

Headache was assessed by a linear analogue scale. The ends of a $10 \mathrm{~cm}$ line signified no and maximal headache, and the subjective experience was indicated on the line and graded in millimetres.

\section{STATISTICS}

As the group was small and the data were not always symmetrically distributed, non-parametric statistical tests were preferred. For comparison of the paired and between group data, Wilcoxon's two sided test was used, or a sign test. ${ }^{6}$ For correlation studies Spearman's rank correlation test was used. A $p$ value below 0.05 was considered significant.

\section{Results}

\section{MAIN STUDY}

Variation during work-GTN was not detected in any morning blood sample, and table 1 gives the plasma values from workers during their normal exposure. At the roll mill area all the blood samples obtained at $1 \mathrm{pm}$ contained more GTN than the one taken at $9 \mathrm{am}$. At the press area all but three increased. Thus the concentration of GTN in the cubital vein increased significantly during work $(p<$ $0 \cdot 001$ ). Significant correlations were found between the values obtained at 9 am and $1 \mathrm{pm}$. At the rolis mill area the correlation coefficient was 0.62 ( $p$ $0.01)$ and at the press area $0.60(p<0.01)$. Wher one subject had a change in plasma GTN concentration between 9 am and $1 \mathrm{pm}$, the companion had a change in the similar direction in 19 cases and in the opposite direction in two; there was no change in two $(p<0.05)$. For each individual, the plasma GTN concentration was higher in the roll mill area than in the press area in 90 of 94 samples ( $p<$ 0.001).

Variation between days-From the first to the second day a significant increase was observed in the 9 am samples from both areas $(p=0.02)$, whereas no significant change was noted for the $1 \mathrm{pm}$ specimens (table 1). Between the first and second day plasma GTN values correlated significantly both at the roll

Table 1 Plasma glyceryl trinitrate (GTN) concentration in nmol/l in blood from the cubital vein of 12 exposed workers. Blood was collected twice a day during work, and at successive days at each of the two production sites

\begin{tabular}{llllll}
\hline Sampling time & \multicolumn{2}{l}{ Roll mill area } & & \multicolumn{2}{l}{ Press area } \\
\cline { 2 - 3 } & Median & Range & & Median & Range \\
\hline Day 1 9 am & $15 \cdot 0$ & $0 \cdot 4-91$ & & $0 \cdot 4$ & $0-9$ \\
Day 2 9 am & $22 \cdot 9$ & $4-246$ & & $15 \cdot 0$ & $0 \cdot 4-40$ \\
Day 1 1 pm & $61 \cdot 2$ & $4-519$ & & $15 \cdot 0$ & $2-113$ \\
Day 2 1 pm & $98 \cdot 1$ & $9-330$ & & $19 \cdot 4$ & $3-49$ \\
\hline
\end{tabular}


mill area $(\mathrm{r}=0.77, \mathrm{p}<0.001)$ and at the press area $(r=0.57, p<0.01)$. Comparing samples collected at a similar time on successive days, the two companions had a change in GTN concentration in the same direction in 14 cases and in the opposite in four cases only $(\mathrm{p}<0.05)$.

Variations between individuals-At each site of production, the individual GTN concentration in the plasma was compared with those of their colleagues and given a rank number. Four rank numbers were thus obtained for each individual at each site, and the sum of the rank numbers obtained at the roll mill correlated with that of the press area $(r=0.73, p<$ 0.02 ) illustrating the individual factor. There was no significant difference between the GTN concentrations in men and women, or between smokers and non-smokers.

\section{CONTROL STUDY}

At the roll mill area one worker had $1015 \mathrm{nmol} / \mathrm{l}$ of GTN in blood from the cubital vein and $11 \mathrm{nmol} / \mathrm{l}$ in blood from the femoral vein. His companion had 115 and $4.8 \mathrm{nmol} / \mathrm{l}$ respectively. One worker at the press area had a concentration of $20.7 \mathrm{nmol} / \mathrm{l}$ in blood from the cubital vein and $4.4 \mathrm{nmol} / \mathrm{l}$ in blood from the femoral vein.

\section{TEST DOSE STUDY}

After receiving $1 \mathrm{mg}$ GTN sublingually in the morning, six of the 12 workers had transient pallor and lightheadedness, but all recovered after a short rest. The maximal plasma GTN concentration of 6.6 $\mathrm{nmol} / \mathrm{l}$ (median $5 \cdot 7$, range $2 \cdot 6-21 \cdot 6$ was found six minutes after adminstration (median 6, range 4-10 minutes). The plasma half life was 3.0 minutes (median $3 \cdot 0$, range $2 \cdot 0-4 \cdot 3$ ). No significant correlation was found between the maximal plasma GTN concentration and the half life.

\section{AIRBORNE GTN CONCENTRATIONS}

The assay of gaseous GTN showed a fourfold variation between successive samples collected within minutes at the same area. Gas samples were obtained on only 28 of the 48 blood sampling occa- sions. At the roll mill area gas was collected at three sites: at the outlet fan, by the cutting machine, and at the heater. The mean values were similar: $2 \cdot 2$, $2 \cdot 1$, and $2.5 \mathrm{mg} / \mathrm{m}^{3}$ respectively. On six days, observations were made at both 9 am and $1 \mathrm{pm}$, and no significant difference was found. Mean values were 2.3 and $2.7 \mathrm{mg} / \mathrm{m}^{3}$ respectively and ranges $1.0-4.0$ $\mathrm{mg} / \mathrm{m}^{3}$. Thus gaseous GTN exposure seemed to be equal at both production sites, and remained unchanged during the day.

\section{BLOOD PRESSURE AND PULSE RATE}

The results of the investigations are shown in table 2.

\section{HEADACHE}

None of the subjects suffered from morning headache. During working hours, however, headache was a major discomfort, increasing during the day. Of the 12 volunteers, only four reported a headache at 9 am any day, whereas 11 had headache by $1 \mathrm{pm}$ on at least one of the days. In fact, only 13 of the 47 inquiries at this time of the day showed absence from headache. At 9 am the mean headache score was $2 \mathrm{~mm}$, increasing to $17 \mathrm{~mm}$ (range 0-59) at the roll mill area; at the press area, the increase was from 3 to $18 \mathrm{~mm}$ (range 0-59). Both increases were significant at the $5 \%$ level. The headache score did not differ between the working sites or between days one and two. The seven smokers were similar to the non-smokers in this respect, and there was no sex difference in the pattern. Between days one and two the headache score did not correlate for each individual and no correlation was found between headache felt at the two sites of work, or by comparing the symptoms of the two companions working together.

\section{CORRELATIONS \\ GTN correlation in room air versus cubital plasma concentration-No significant correlation was found. \\ GTN concentration in plasma on exposure at work versus GTN kinetics after a sublingual test dose-The plasma GTN concentration of the pairs of workers at $1 \mathrm{pm}$ was compared and given a rank number.}

Table 2 Pulse rate and systolic blood pressure in 12 workers before and during work on two successive days of exposure to glyceryl trinitrate

\begin{tabular}{|c|c|c|c|c|c|c|}
\hline \multirow[t]{2}{*}{ Working site } & \multicolumn{3}{|c|}{ Pulse rate } & \multicolumn{3}{|c|}{ Blood pressure (systolic) } \\
\hline & Mean & $1 \& 21$ & Range & Mean & $1 \& 2)$ & Range \\
\hline $\begin{array}{l}\text { Before work } \\
9 \mathrm{am} \text { at press area } \\
9 \mathrm{am} \text { at roll mill area } \\
1 \mathrm{pm} \text { at press area } \\
1 \mathrm{pm} \text { at roll mill area }\end{array}$ & $\begin{array}{l}73 \\
87^{* *} \\
84^{* *} \\
87^{* *} \\
86^{* *}\end{array}$ & $\begin{array}{l}72 \\
92 \\
84 \\
85 \\
84\end{array}$ & $\begin{array}{l}60-90 \\
64-104 \\
60-116 \\
68-108 \\
72-100\end{array}$ & $\begin{array}{l}124 \\
125 \\
119 \\
119 \\
115^{*}\end{array}$ & $\begin{array}{l}125 \\
125 \\
120 \\
120 \\
115\end{array}$ & $\begin{array}{l}95-150 \\
90-150 \\
95-150 \\
90-145 \\
90-160\end{array}$ \\
\hline
\end{tabular}

${ }^{*} \mathrm{p}<0.05 ;{ }^{* *} \mathrm{p}<0.01$. 
Each subject thus had four rank numbers that were added to give an estimate of tendency towards obtaining a high or low concentration of GTN in the arm vein. This rank sum correlated neither with plasma half life nor with the maximal GTN concentration observed after sublingual GTN.

GTN concentration in plasma versus blood pressure and pulse rate-Plasma GTN concentration correlated with neither change in pulse rate nor with change in blood pressure during work.

GTN concentration in plasma versus headache score-No significant correlation was shown.

Headache versus change in blood pressure and pulse rate-The correlations were not significant.

\section{Discussion}

During treatment with GTN, plasma concentrations are usually in the range $2 \cdot 2-44 \mathrm{nmol} / \mathrm{l}$. Among the present workers, cubital vein plasma concentrations showed a 10-fold increase over therapeutic levels. Concentrations in blood from the femoral vein were much lower, strongly suggesting that the local absorption of GTN through the skin of the hands and arms was an important factor. This has previously been shown for ethylene glycol dinitrate, ${ }^{7-8}$ the main component of dynamite. It is well known that GTN is absorbed through the skin and use is made of this in "transdermal infusion systems." The workers are well aware of this absorption, but despite frequent changes of gloves and other measures, adequate protection was not gained. Contamination of samples during blood collection is not likely considering the precautions taken and the correlations between day to day samples.

The site of production was important, since the values found at the roll mill were consistently higher than those at the press area. At both sites the plasma GTN concentration increased during the day from an initial level of zero in the morning. Since the concentration of gaseous GTN was similar at the various sampling times, this observation is compatible with a cumulative dermal contamination during the day, and further supported by the correlation observed between the values obtained at 9 am and 1 pm.

After the sublingual administration of GTN a plasma half life of three minutes was observed. This is somewhat less than the 4.4 minutes reported by Armstrong and coworkers, ${ }^{9}$ who studied healthy volunteers. Any large increase in GTN metabolism, however, does not seem to have evolved in the present workers. The pulse rate was higher during work than in the morning, but no further increase took place during the day, despite the significant increase in plasma GTN. This might suggest that it was the work itself rather than exposure to GTN that was responsible for the increase in pulse rate. The slight reduction in systolic blood pressure when the plasma GTN was maximal, however, favours the effect of GTN. ${ }^{10}$ "Headache was the main discomfort, and was experienced by 11 of the 12 workers; they often needed analgesics to continue work. The pronounced and significantly increasing headache seemed to be directly related to exposure although the degree of headache was similar in both the high and low exposure areas. We have no explanation for this observation. The discomfort felt by half the volunteers after a test dose of $1 \mathrm{mg}$ GTN sublingually was also remarkable. This part of the study was done on a Monday morning, when headache after exposure to GTN is more severe than later in the week.

Gaseous GTN has been considered the main risk to the workers' health, and the safety rules are based on measurements of this component. Nevertheless, the variation in the concentration of GTN in air samples from minute to minute, in addition to variations in sampling and analytical techniques, cast doubt on the justification of monitoring gaseous GTN as a means of ensuring the worker's health. At the gas concentrations now encountered (1-4 mg/ $\mathrm{m}^{3}$ ) uptake through the lungs probably contributes little to the blood concentration when dermag absorption also occurs. Dermal absorption of gase? ous GTN ought also to be considered, since Hogs tedt and Ståhl ${ }^{8}$ showed such an uptake of ethylene? glycol dinitrate. The present study shows that during production of gun powder GTN is dermally absorbed through the hands and arms despite the use of protective clothing. Accordingly blood from the arm veins cannot be used to study total exposure to GTN, although it may be of value for monitoring efforts made towards reducing dermal uptake. The concentrations presently attained in blood from the cubital vein show the importance of the working conditions as well as of individual factors. The latter probably concern the manner and the degree of which GTN is handled during production, since the rate of elimination showed only a moderate variation. The study suggests that major efforts should be made to reduce dermal contact with GTN during work.

\section{References}

' Symanski H. Schwere Gesundheitsschädigungen durch berufliche Nitroglycoleinwirkung. Archiv für Hygiene und Bakteriologie 1952;136: 139-58.

${ }^{2}$ Bille S, Sivertssen E. Sudden death in a dynamite worker. Nord Med 1963;70:842-3.

${ }^{3}$ Lange RL, Reid MS, Tresch DD, Keelan MH, Bernhard VM, Coolidge $\mathrm{G}$. Nonatheromatous ischaemic heart disease following withdrawal from chronic industrial nitroglycerin exposure. Circulation 1972;46:666-8. 
4 Manrique KL, Bredesen JE, Greibrok T. Rapid, isothermal gasliquid determination of nitroglycerin in plasma with use of an electron capture detector. In: Frigerio A, ed. Chromatography and mass spectrometry in biomedical sciences. Vol 2. Amsterdam: Elsevier Scientific Publishing Company, 1983:97-103.

s Saltzman BE. Colorimetric microdetermination of nitrogen dioxide in the atmosphere. Anal Chem 1954;26:1949-55.

- Gindler EM. Some nonparametric statistical tests for quick evaluation of clinical data. Clin Chem 1975;21:309-14.

' Einert C, Adams W, Crothers R, Moore H, Ottoboni F. Expos- ure to mixtures of nitroglycerin and ethylene glycol dinitrate. Am Ind Hyg Assoc J 1963;24:435-47.

${ }^{8}$ Hogstedt C, Ståhl R. Skin absorption and protective gloves in dynamite work. Am Ind Hyg Assoc 1980;41:367-72.

- Armstrong PW, Armstrong JA, Marks GS. Blood levels after sublingual nitroglycerin. Circulation 1979;59:585-8.

${ }^{10}$ Bille S, Sivertssen E. Nitroglycerine and nitroglycol as a health problem in industry. Nord Med 1963;70:837-41.

"Trainer DC, Jones RC. Headaches in explosive magazine workers. Arch Environ Health 1966;12:231-4. 